\title{
Bridging the cultural divide
}

$\mathrm{t}$ was around 5 p.m. on the first Wednesday of November, and I was filing out of Memorial Hall Auditorium amidst a throng of JMU students, faculty, staff and community members who had filled the seats to watch a debate on national security hosted by the Madison Vision Series. I was struck by how uplifted everyone around me seemed as they talked enthusiastically about the debate. You would have thought we were all leaving a movie theater after seeing an entertaining film with a happy ending, rather than a policy debate.

Both debaters, Josh Zive (senior counsel for Bracewell Law) and Daveed Gartenstein-Ross (senior fellow at the Foundation for Defense of Democracies), are skilled orators, with deep expertise in national and foreign policy. In the spirit of civil discourse, they respectfully sparred for over an hour about whether radical change is necessary to confront terrorism. As we left the auditorium, I asked a few attendees what they thought about the debate, and universally they responded by describing how refreshing it was to watch two people disagree on an important and complicated issue without yelling or resorting to ad hominem attacks. Their use of facts, logical arguments and persuasive case-making was in stark contrast to what we all were hearing during the election season.

Reflecting further on the event and the audience's positive response against the backdrop of our fraught national dialogue, I tried to imagine how a people might work together to discover an improved way of life-maybe a new set of activities or rituals that elevate our entire culture and help us all flourish individually and collectively. I'm not suggesting a search for an idealized utopia, because history shows us that is not possible. Rather, I wondered whether we could develop a new, broader and somehow organized national incli-

'.. we work
every day to
instill within our
community the
recognition that
we need each
other, despite
tensions.'

nation to seek renewed purpose and meaning as a culture.

You will notice that the concept of "culture" is a theme in this edition of Madison. Whether it's JMU English professor Mark Rankin's National Endowment for the Humanities-funded research on William Tyndale, one of the most significant writers of the English Renaissance (Page 37); CNN senior White House correspondent Jim Acosta's ('93) commitment to journalistic principles (Page 24); Integrated Science and Technology professor Carole Nash's work in Shenandoah National Park during the centennial of our national park system's founding (Page 28); or the recent tribute to Maya Angelou, presented by the JMU Furious Flower Poetry Center (Page 64) - these manifestations of intellectual accomplishment work to cultivate deeper understandings of our human experience and, in the aggregate, advance culture.

But, let's consider that inherent in each of these examples - and the many others contained in this issue of Madison - is a search for truth among competing interpretations of reality. The truth is not always clear, and not all of us interpret truth in the same way on any given topic, which creates tension. Searching for the truth is at the heart of making sense of our world collectively as a culture, and nearly all of the stories contained in this edition exhibit tension between interpretations of reality.

Dec. 15, 2016, marked the 225th anniversary of the passage of the Bill of Rights, written by the man for whom we are named. James Madison's political brilliance is credited with conceiving a system of government that has lasted longer than any other in human history. At the most basic level, Madison's political genius was to recognize our human shortcomings and design a system that would counterbalance all of our competing interests. It was the healthy tension between citizens' various interpretations of the truth that would keep any one interpretation from dominating others. Such an arrangement has worked ever since and has seen us through many challenges and crises.

Here at James Madison University, we work every day to instill within our community the recognition that we need each other, despite tensions. For the system of government conceived by Madison to survive, we must educate our students to understand that as citizens, we are in this together. And if we truly understand and respect that our individual rights come with the responsibility that we accept the rights of others - and the inherent tensions between us - we may indeed survive and thrive as a nation and advance as a culture.

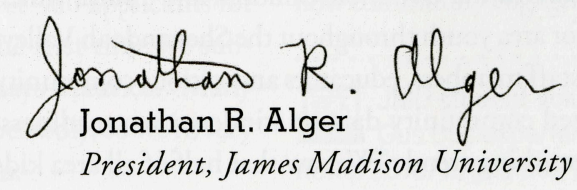

